\title{
Glass-reinforced steel structures
}

\author{
Kars Haarhuis • Thomas Wever
}

Received: 30 November 2015 / Accepted: 12 April 2016 / Published online: 26 April 2016

(C) Springer International Publishing Switzerland 2016

\begin{abstract}
In search for more transparency, sustainability and more slender structures, new methods are needed to use the load-bearing capacity of structures more efficiently. In two buildings, described in this paper, structural glass is successfully applied to increase the steel structure capacity, leading to less material usage and more transparency. The glass is providing stability to the structure by in-plane lateral loading, resulting in a glass-reinforced steel structure without the need for any steel braces. In both projects, the glass detailing is designed pragmatically, so similar future projects can benefit from this development. Additional research is currently in progress for application of in-plane loaded glass in high-rise buildings.
\end{abstract}

Keywords Glass · Steel structures · In-plane loaded glass $\cdot$ Stability $\cdot$ Diagonal $\cdot$ Braces

\section{General}

\subsection{Paradox}

Steel is the most common material to connect glass elements. For example, point-fixed glazing is often connected with steel members that preferably should be as small as possible. But why are we trying to eliminate the steel, if much more interesting structures can

K. Haarhuis $(\varangle) \cdot T$. Wever

ABT bv, The Hague, The Netherlands

e-mail: k.haarhuis@abt.eu be realized by doing the exact opposite? What if we take a large scale steel structure and turn it into a slender design with reduced section sizes, just by adding glass elements? The glass makes it possible to build impressive steel structures. For example, it can be used to reduce buckling lengths for slender columns, replace braces with glass panes, or replace entire concrete walls with glass elements. Recent developments in two actually realized projects prove the possibilities are yet to be fully explored.

\subsection{Subject and similar developments}

In order to introduce the concept of glass-reinforced steel, this paper focuses on the application of inplane loaded glass in steel structures. Earlier research revealed the capacity of in-plane loaded glass (Huveners et al. 2007). Also, several structures and glassreinforced steel members have been studied (Englhardt 2007; Netusil and Eliasova 2012). In many cases, adhesives were used to establish a (linear) connection between the steel and the glass (Mocibob and Crisinel 2008). Other similar projects were either fully made out of glass with bolted connections (Nijsse 2012) or were part of buildings like entrance canopies or roofs (Kruijs 2010; Weller et al. 2010; Wellershoff 2007). Also prestressed glass structures have been studied (Freitag and Woerner 2009). The two projects described in this paper can be considered as the next step in these developments in a practical manner, by using regular building 
components like rubber setting blocks and mortar to transfer the forces between the steel and glass. These developments could be used for actual architectural purposes in the near future (Fig. 1).

\section{The glass pavilion 'De Boerderij'}

\subsection{Architectural scope}

In May 2015 construction finished of a glass pavilion which is part of restaurant 'De Boerderij' ('the farm') in Arnhem, NL. For the historical area of the park, the architect's goal was to design a maximally transparent and light-weight farm shed. Traditional sheds in the surrounding area were usually made of wood with large openings for the farm machinery. Since a structure of wood would result into heavy cross-sections, the architect suggested to use steel hidden within a 10 $\mathrm{mm}$ thin wooden casing.

The structural optimization showed a column size $80 \times 80 \times 8$ was feasible, but demanded an appropriate stabilizing structure in the façade to transfer the lateral wind loads. Regular braces were not an option, since the view on the surrounding park should be preserved as much as possible. At this point it was proposed using in-plane loaded glass elements to reinforce the steel structure. Many years of experience in engineering of glass structures were enough to prove the possibilities of the concept in the early design stages. Within a regular timeframe, the project program and permits were arranged (Fig. 2).

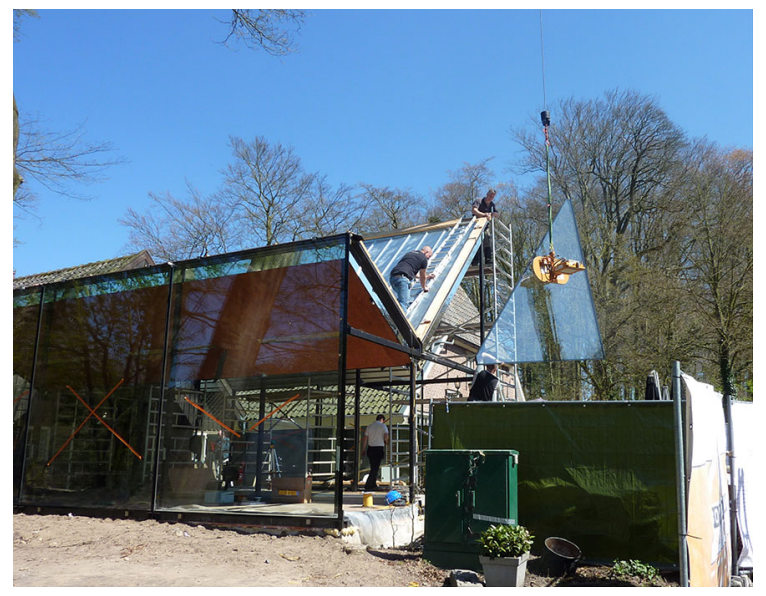

Fig. 1 Situation during construction of De Boerderij

\subsection{Glass possibilities}

In the early design stage, the capacity of the glass elements was globally analysed and gave enough confidence for actual application in the building. A regular PVB-laminated panel 8/8/2 (8+8 $\mathrm{mm}$ glass, $0.76 \mathrm{~mm}$ PVB) of approximately $2 \times 3 \mathrm{~m}$ heat strengthened glass, was able to transfer diagonal loads of maximum of approximately $20 \mathrm{kN}$ without plate buckling effects. These results were based on a level of composite action applicable for short term loading during wind actions ( $5 \mathrm{~s}$ according to the Dutch regulations, i.e. NEN 2608:2011). Also, initial imperfections were taken into account in accordance with EN 12150-1 (12 $\mathrm{mm}$ in the center area) as well as consideration of construction deviations for all SLS and ULS load cases. In order to determine second order effects appropriately, geometrical non-linear analysis has been performed. Since the analysis considered both the complete building as well as the glass components, the calculations have been performed based on an equivalent thickness for the laminated panels, in accordance with NEN2608:2011. These thicknesses were incorporated in the software, SCIA Engineer 2013. The stresses in the overall system were analysed carefully, since they depend on the stiffness and interaction of the overall structure (see 2.4: Suitable glass supports) (Fig. 3).

\subsection{Detailing conditions}

The next step was to determine appropriate detailing which would fit both the architectural scope and the structural boundary conditions. Also, the following conditions had to be met:

- Insulated glass units

- Regular thickness for wind loads (8/8/2 PVB inner panel-16 mm cavity $-8 \mathrm{~mm}$ outer panel)

- Economical supports without point-fixations

- Possibility of load introduction on non-rectangular glass panes.

- Adjustment possibilities for fixation

- Out of plane fixation of the glass

- Free space of about $100 \mathrm{~mm}$ between the glass and steel structure

The basic idea was to apply regular setting blocks for transferring loads from the steel to the glass and vice versa. Those setting blocks would be easy to install. 


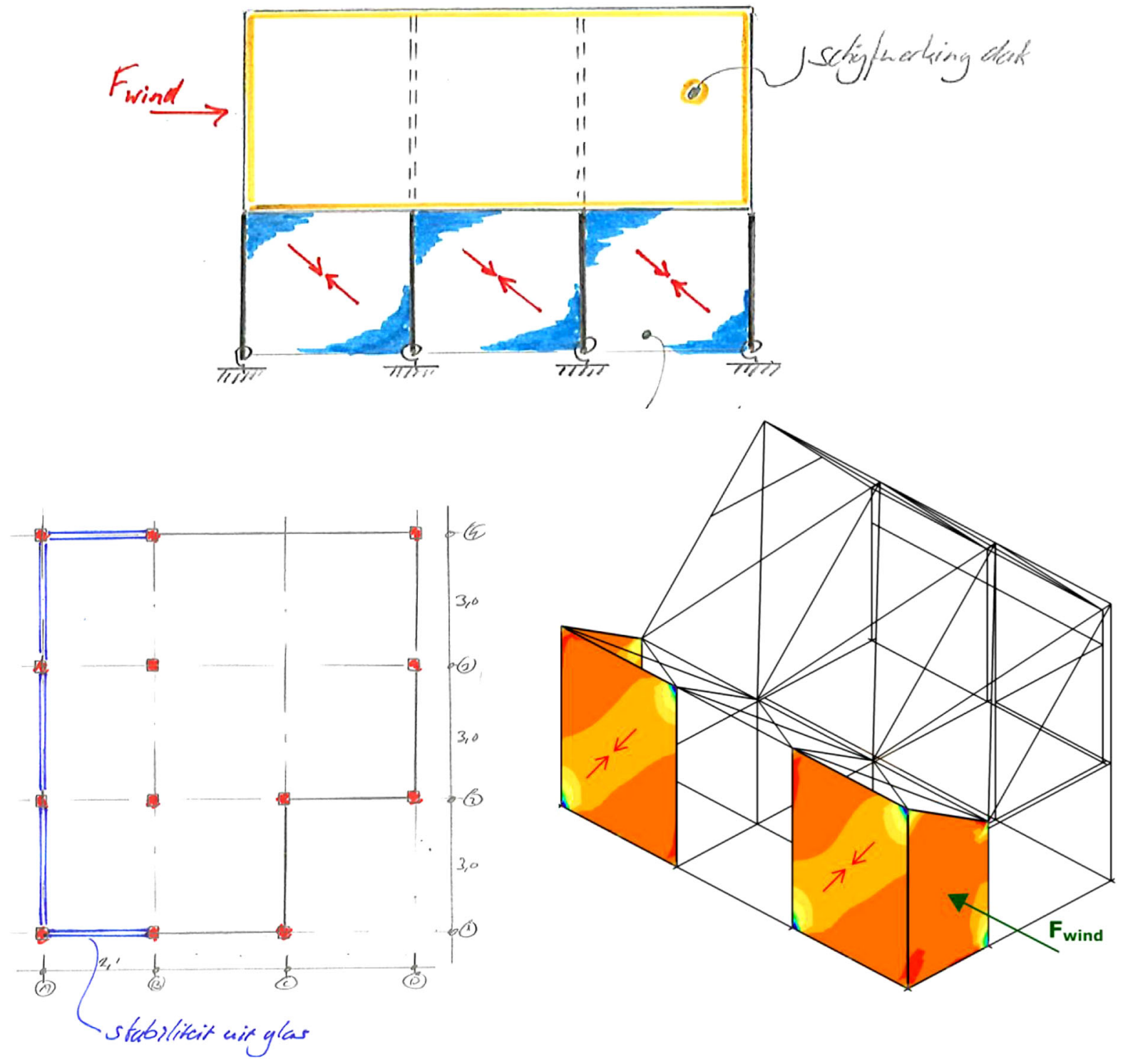

Fig. 2 Schematical view of the overall structure with in-plane forces ('schijfwerking')

Also they could be manufactured with the right stiffness, necessary to distribute the forces equally over the glass edges. The setting blocks made it possible to transfer only compression forces on the glass edges without the need of complex steel connections or any adhesive. Since the compression strength of the glass is higher than the tensile strength, this is an ideal situation from a structural point of view. The glass is locked inside a frame with setting blocks, strong enough to transfer the load, yet flexible enough to distribute forces and allow slight temperature deformations.
Regular glass facades would have been installed with setting blocks at the bottom edge only. For introduction of the in-plane forces, the blocks were necessary at all corners. Lateral forces could be transferred in both directions. By positioning the blocks against steel T-sections, which were welded to the steel main structure, a clear structural system was obtained (Figs. 4, 5). By this time, the glass supplier was already involved in the project and agreements were made about glass tolerances such as edge shift deviations. As a consequence, all glass elements were produced with tight 

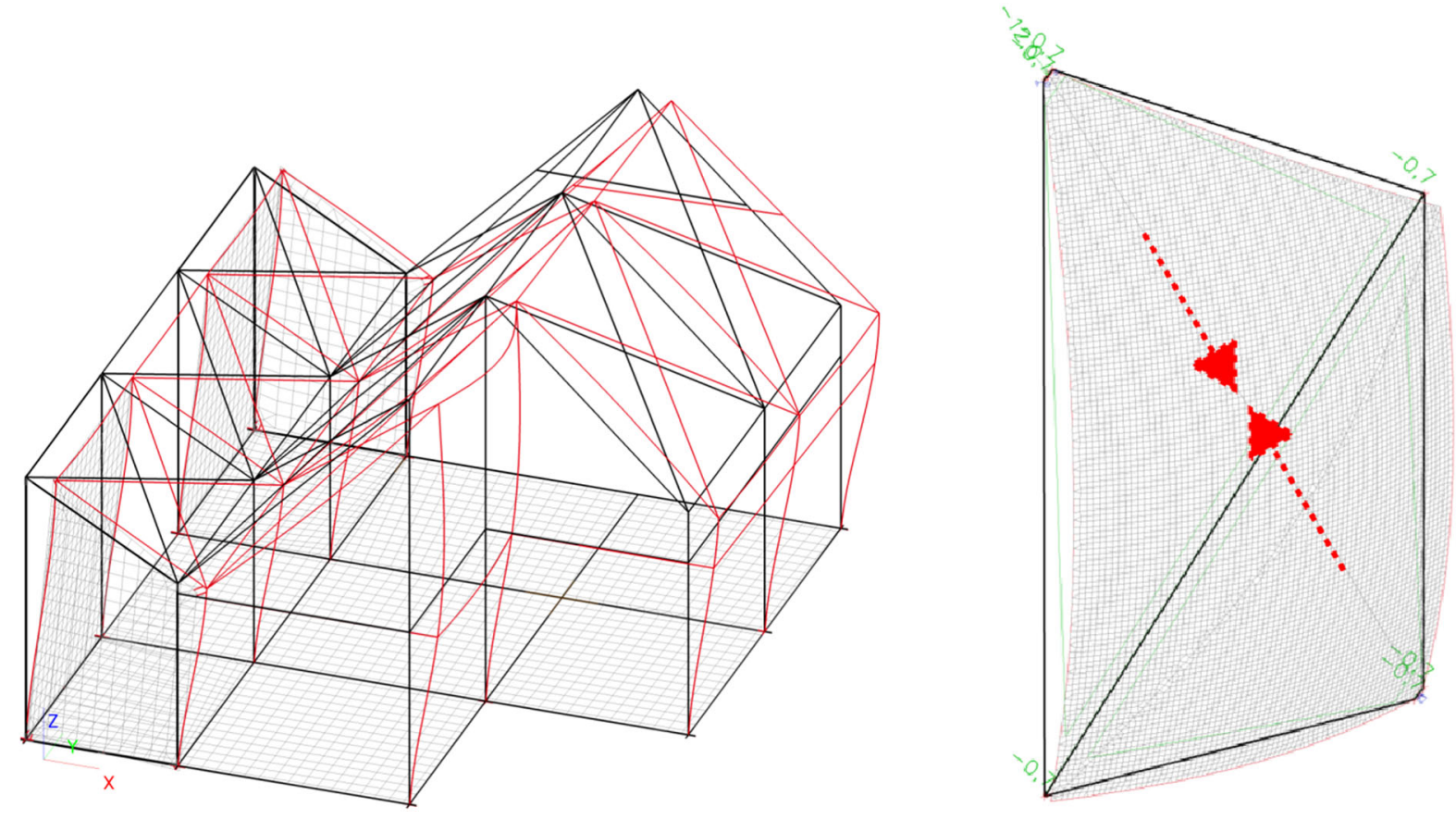

Fig. 3 Analysis of the overall structure and plate buckling

Fig. 4 Left regular positioning of the glass with setting blocks only at the bottom edges. Right In-plane glass forces with setting blocks at all corners. An edge distance of $10 \mathrm{~mm}$ was applied, which is slightly more than the glass thickness and found to be acceptable

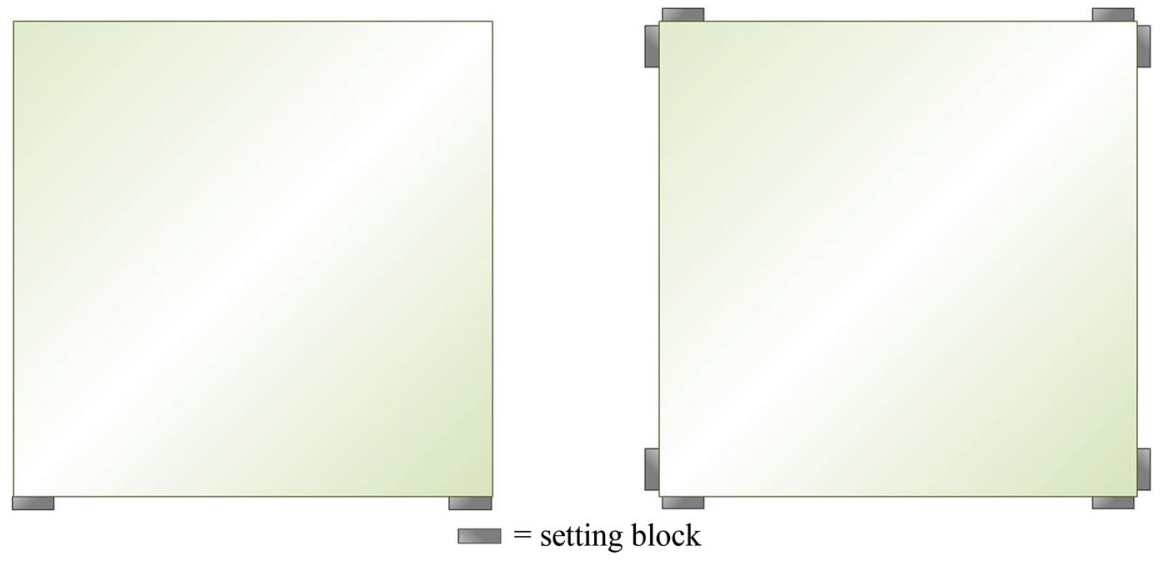

tolerances. Gaps, if any, were filled out with multiple thin setting blocks.

\subsection{Suitable glass supports}

In order to distribute forces equally over the glass edges and avoiding too high stresses at the same time, research has been conducted for the most suitable material for the setting blocks (Table 1). Regular EPDM was found to be too weak for transferring the forces of approximately $20 \mathrm{kN}$ without deforming too much. On the other hand, POM was found to be too stiff and would cause high stresses in the glass elements. After experimental testing, the right material was found to be polyester-polyurethane. This material deformed approximately $1-2 \mathrm{~mm}$ during a $10 \mathrm{~min}$ compression test with a plate size of $100 \times 20 \times 8 \mathrm{~mm}^{3}$. In the numerical models this test result has been incorporated by an equivalent modulus of elasticity of $40 \mathrm{~N} / \mathrm{mm}^{2}$ for the specific members. 


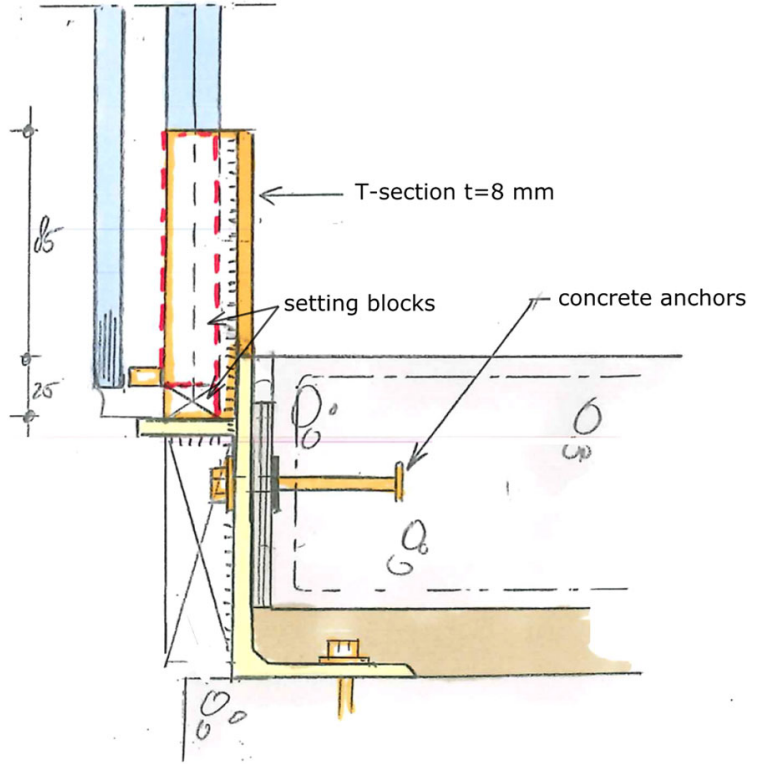

Fig. 5 Steel strips with setting blocks (red) placed in the joint between two windows for transferring horizontal loads to the steel structure. (Color figure online)

The setting blocks have all been placed at a slight distance of $10 \mathrm{~mm}$ out of the glass corners so peak stresses in the weaker glass corners would be avoided.

\subsection{Additional glass conditions}

While the glass supports could be applied at almost all panels, some other practical issues had to be resolved. For instance the method of supporting the outer panel of the insulated glass. Only the inner glass panel is designed to carry the lateral wind loads from the steel structure, since this is the laminated panel. In case of failure, the laminated panel is be able to retain its integrity. This means the outer panel could be connected just by the spacers to the glass, which enables the outer panel to deform a bit more easily under temperature loads. The applied spacers are able to carry the glass load of the outer panel, and even if these spacers lose their load-bearing capacity, the appearance of moisture within the cavity would reveal the spacer is not functioning appropriately any longer. The combined experience and knowledge of the engineering firm and glass supplier gave enough confidence for a secure application.

All glass panels are positioned on at least two setting blocks on steel plates of $100 \mathrm{~mm}$ which are welded to the main structure (Fig. 5). Positioned next to these steel plates, vertical steel plates are inserted in the glass cavity edges for horizontal fixation of the glass (Fig. 6). Special attention was needed for transferring the lateral forces at the building corners. A T-section such as shown in Fig. 5 would not fit in the corner. Therefore, a solid steel bar $(30 \times 30 \times 120)$ was welded on the corners of the steel structure and after glass installation hidden inside the corner detail (Fig. 7).

\subsection{Structural safety}

With knowledge of the capacity of the glass and appropriate detailing, it became clear the overall structural stability could be provided completely by the glass. It turned out the glass capacity of just 4 glass units was sufficient. Some other glass elements were also able to transfer lateral loads, but in case of failure of one or more glass elements (or a single glass sheet) the structural safety of the overall structure is still ensured in case those 4 or more glass units remain intact. Additional models were also made to prove that ULS requirements were also satisfied with the theoretical case of a structure with only steel without any glass. Although the steel would not be yielding, the deformation was over 3 times higher than the allowed maximum. This proves the slender steel structure and

Table 1 Setting blocks: comparison of deformation under compression loads (FEA results)

\begin{tabular}{llllll}
\hline Specimen & Material & Section dimensions $(\mathrm{mm})$ & Force $(\mathrm{kN})$ & Compression $\Delta L[\mathrm{~mm}]$ & Glass stress $\left(\mathrm{N} / \mathrm{mm}^{2}\right)$ \\
\hline 1 & EPDM & $100 \times 20 \times 8$ & 20 & $\sim 7$ & $-^{\mathrm{a}}$ \\
2 & Polyester-polyurethane & $100 \times 20 \times 8$ & 20 & $\sim 2$ & $\sim 20.0$ \\
3 & POM & $100 \times 20 \times 8$ & 20 & $\sim 0.1$ & $\sim 25.0$ \\
4 & Aluminum & $100 \times 20 \times 8$ & 20 & $\sim 0.001$ & $\sim 50.0$ \\
\hline
\end{tabular}

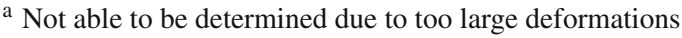




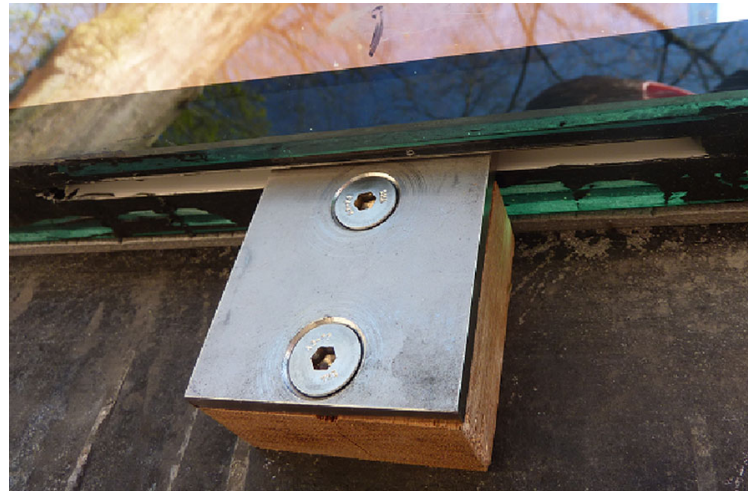

Fig. 6 Horizontal fixation of the glass
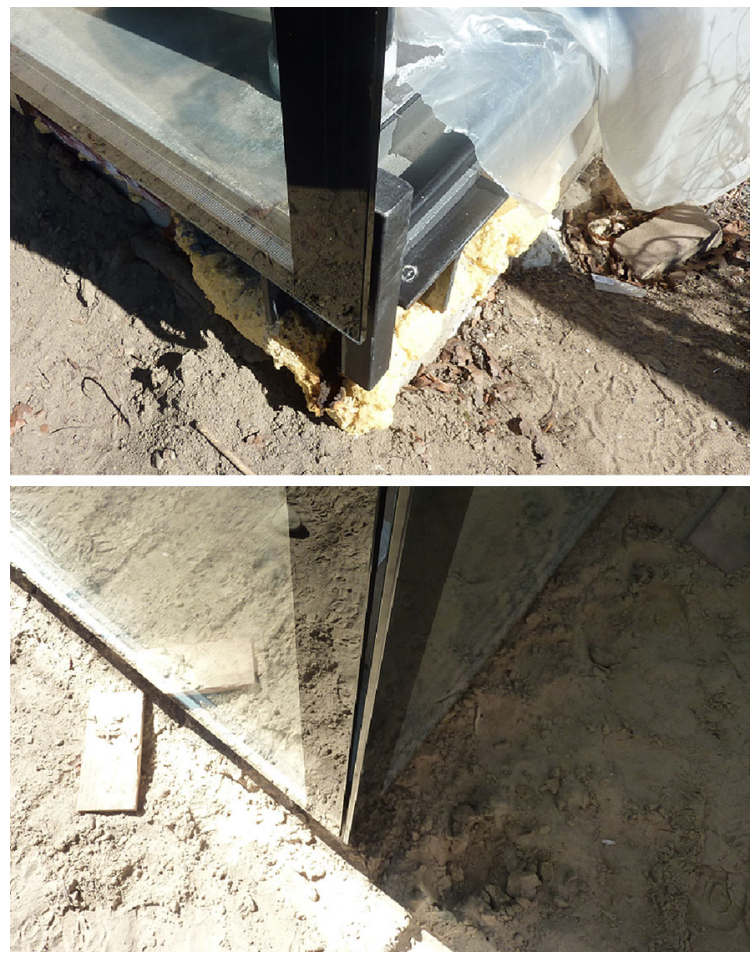

Fig. 7 Corner detail: during construction (top) and after closing (bottom)

SLS requirements were only satisfied due to application of the glass elements.

\section{Goudaglass canopy}

\subsection{Architectural scope}

Another extraordinary application is the in-plane loaded glass roof of the Gouda train station canopy (NL,

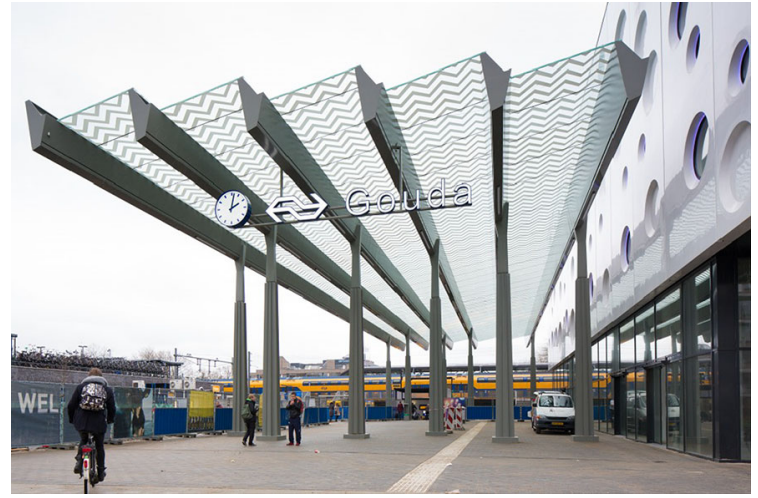

Fig. 8 Gouda train station canopy

2015). In this case, the architect was wondering if the steel beams ( $1.2 \mathrm{~m}$ height) could cantilever up to $14 \mathrm{~m}$, and by doing so spanning almost fully towards the side of the train platforms. A new way was found to give lateral support to the steel beams by using glass between the steel beams, which avoids regular bracings and made it possible to realize the architectural vision within the budget (Fig. 8).

\subsection{Glass possibilities}

The stability of the structure is provided by stiff columns that are clamped into the foundation. On top of the columns a fixed connection is made with the beams. The span is as large as $32 \mathrm{~m}$, which means the beams would deform in both vertical (strong axis) and lateral direction (weak axis). The deformation increases due to the slight leaning angle of the beam. As a consequence of using different spans, the beams would show different deflection patterns in lateral direction under self-weight and would lead to a maximum lateral deformation of $33 \mathrm{~mm}$ for a single beam. That is the case if no glass would have been applied (Fig. 9). The deformations in lateral direction would increase due to snow loads and could easily damage the glass in a regular case. The glass was therefore needed to reduce these deformations. In order to satisfy safety requirements, laminated tempered glass was used. The glass stresses in the global model (see Sect. 3.3) allowed the application of heat-strengthened glass, which would have been more favorable for post-breakage behavior. However, the local concentrated loads for maintenance issues 
Fig. 9 Theoretical situation without glass: enlarged lateral deflections under self weight

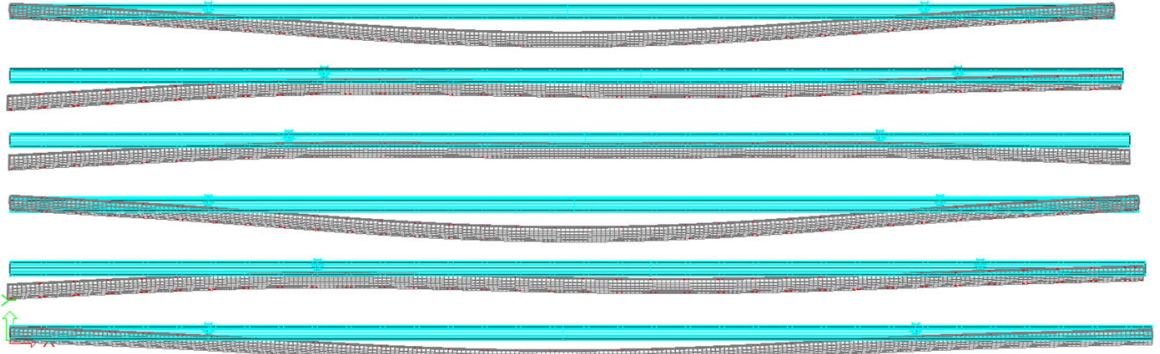

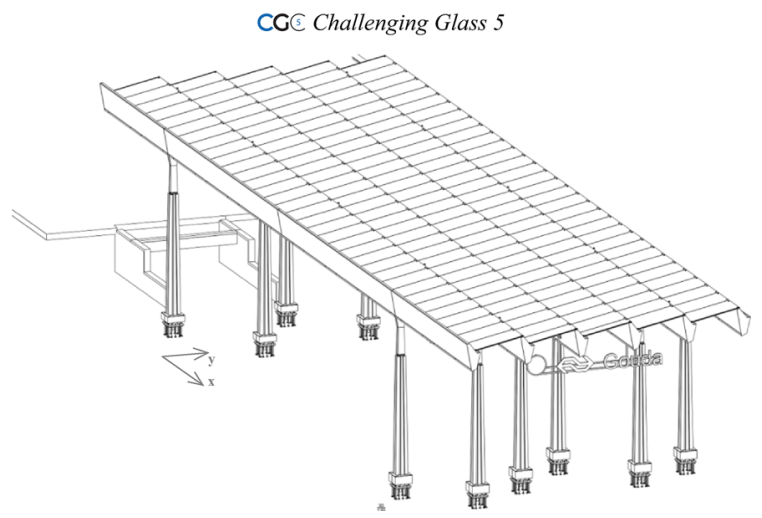

Fig. 10 Gouda train station 3D steel structure (no foundation). Glass span and stability performance in y-direction

$\left(1.5 \mathrm{kN}, 100 \times 100 \mathrm{~mm}^{2}\right)$ required the strength of tempered glass (Figs. 9, 10).

The previously described beam behaviour made clear regular infill frames of glass would not be sufficient. Already in the early design stages, glass was considered as an option for providing extra stiffness in the roof surface. Further analysis revealed that not the selfweight of the steel beams would lead to the highest deflections, but wind loads on the front beam over the full height of $1200 \mathrm{~mm}$ would give the highest lateral deformations. Other beams would be affected less, but would still deform under self-weight deformations. The deformations due to wind actions could increase up to $130 \mathrm{~mm}$ for the front beam if no glass support was applied (Fig. 11).

In order to reduce the deflections to acceptable values, the glass was used to act as a rigid floor diaphragm over the full roof surface. This resulted into a glass structure that is reinforcing the beams by distributing wind loads to all beams (Fig. 12). The span of a single glass pane is approximately $2.5 \mathrm{~m}$.

\subsection{Detailing conditions}

The glass was originally considered to be connected to the steel with a linear adhesive support. Because of support rotations and for practical reasons, such as construction and replacement considerations, soon the option of using point fixed glass became more interesting. The roof panels consists of 12/12/4 PVB-laminated tempered glass ( $12+12 \mathrm{~mm}$ glass, $1.52 \mathrm{~mm}$ PVB). This was enough to reduce the stresses near the connections to less than $10 \mathrm{MPa}$ and avoid any high deformations under self-weight and interlayer relaxation. The overall in-plane stresses remain quite low due to the large glass area. Based on the normal force in a single glass pane of approximately $3.5 \mathrm{kN}$ (ULS), the normal stress reaches up to $5 \mathrm{~N} / \mathrm{mm}^{2}$. The detailing was realized with a bolt connection into mortar-filled glass holes (Fig. 13).

\subsection{Construction phase}

A challenging part was the assembly of the overall structure. Since the steel beams were not able to carry their self weight without too large deformations in lateral direction, temporary braces were added. Specific glass assembly phases were precalculated to introduce as little stress as possible in the glass during installation. This phased assembly method also made sure the stresses in the end situation were acceptable when the complete canopy was installed.

\section{Conclusion}

In both the pavilion 'De Boerderij' and the Gouda glass canopy, the capacity of the steel structure has been increased by using in-plane loaded glass. Finite element analysis showed relatively low stresses occurred 
Fig. 11 Theoretical situation without glass: lateral deformations due to wind loads over $130 \mathrm{~mm}$ in the front beam
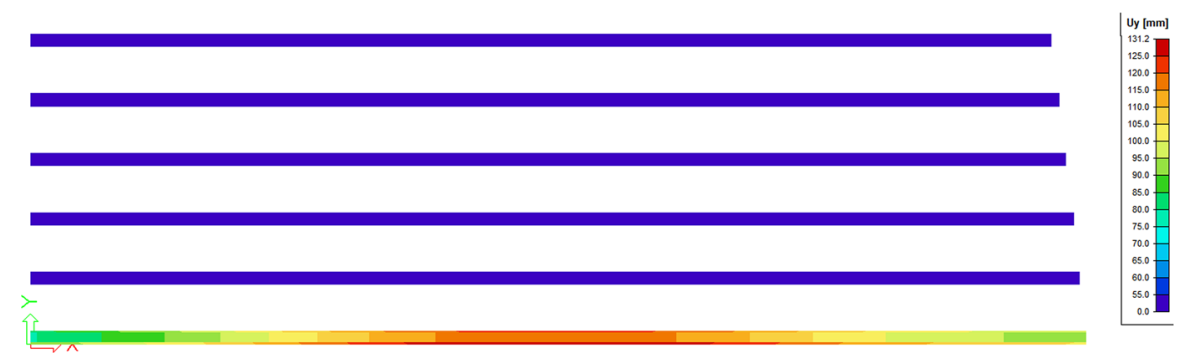

Fig. 12 Actual situation with glass: lateral deformations reduced to $57 \mathrm{~mm}$

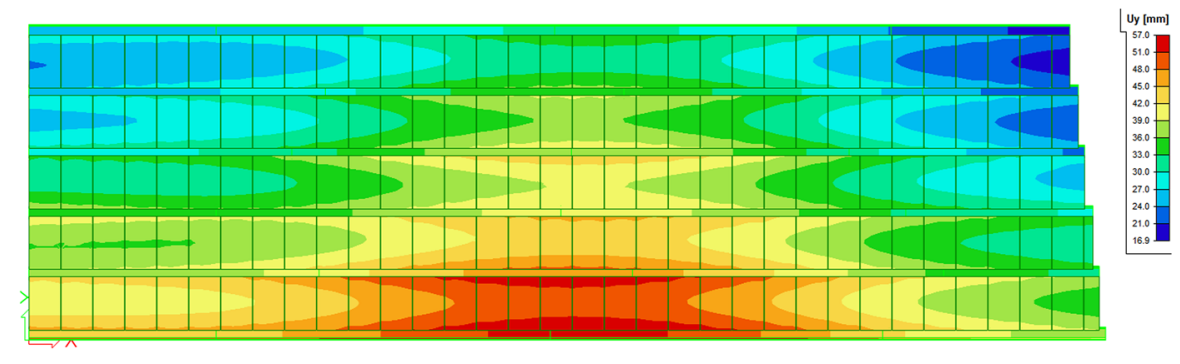

Fig. 13 The glass elements are point-fixed. Before glass installation, temporary braces were added to ensure lateral beam support
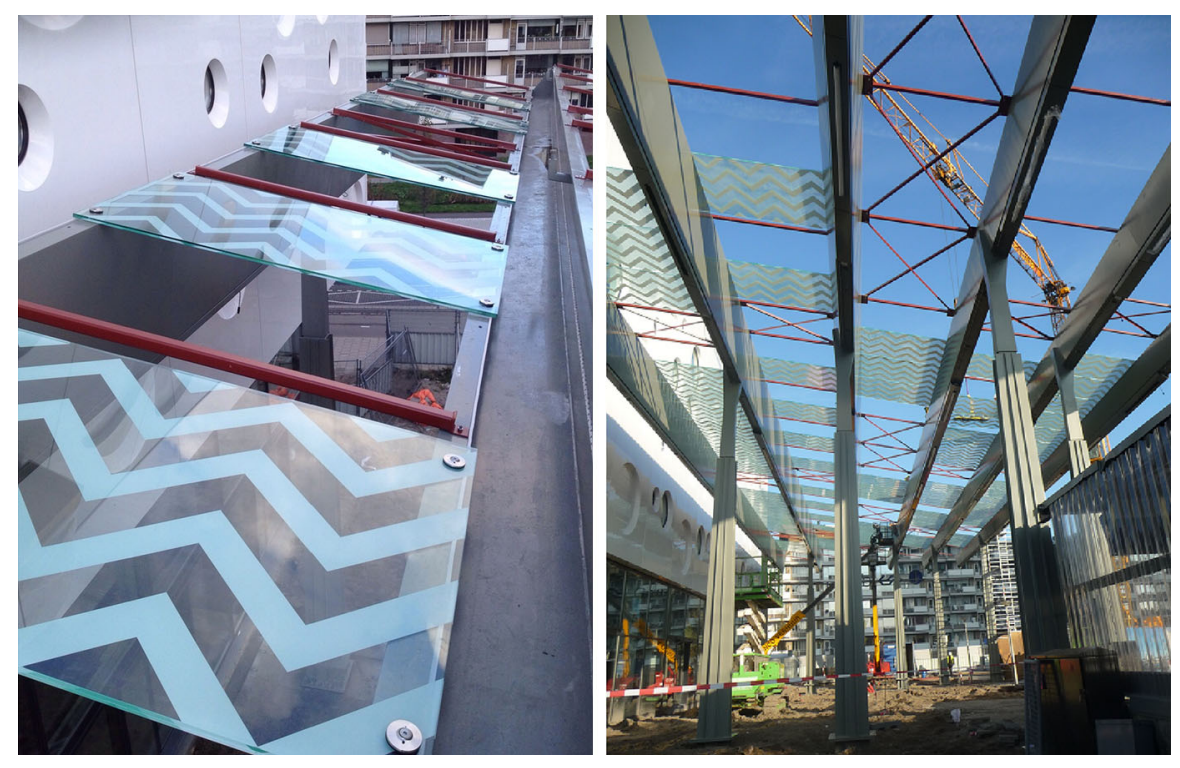

in the glass by using the appropriate detailing. This resulted in two unique glass-reinforced steel structures without the need of steel braces.

The research on glass-reinforced steel structures is still in progress. For example by collaborating with universities to explore the next challenge: glass in highrise structures. One of the major issues to be researched is fire safety of glass structures in multi-storey buildings.
Acknowledgments These glass developments have become reality due to the dedication and support of many colleagues. We would like to thank each one of them.

\section{Compliance with ethical standards}

Conflict of interest On behalf of all authors, the corresponding author states that there is no conflict of interest. 


\section{References}

Englhardt, O.: Flächentragwerke aus Glas-tragverhalten und stabilität. Dissertation, Universitätfür Bodenkultur, Wien (2007)

Freitag, C., Woerner, J.D.: Glass as structural bracings-shear capacity of mechanically pre-stressed windowpanes. Glass Performance Days 2009, pp. 333-337 (2009)

Huveners, E.M.P., Herwijnen, F., Soetens, F., Hofmeyer, H.: Glass panes acting as shear wall. Heron, 1/2, 52 (2007)

Kruijs, R.: Glazen platen als windverband. Glas in Beeld 201002, 28-29 (2010)

Mocibob, D., Crisinel, M.: Linear connection system for structural application of glass panels in fully-transparent pavilions. In: Bos, F., Louter, C., Veer, F. (eds.) Challenging Glass, pp. 253-261. Delft University Press, Delft (2008)
Netusil, M., Eliasova, M.: Structural design of composite steelglass elements. In: Bos, F., Louter, C., Nijsse, R., Veer, F. (eds.) Challenging Glass 3, pp. 715-734. Delft University Press, Delft (2012)

Nijsse, R.: Glass walls carrying the roof and withstanding the wind load on the façade: conservatory of the museum in Dordrecht and Raaksglass cube in Haarlem. In: Bos, F., Louter, C., Nijsse, R., Veer, F. (eds.) Challenging Glass 3, pp. 111-120. Delft University Press, Delft (2012)

Weller, B., Reich, S.,Ebert, J.: Transparent glass-Vierendeel roof. In: Cruz, Paulo J.S. (eds.) Proceedings of the First International Conference on Structures and Architecture, ISCA 2010, pp. 77-78. CRC Press, Leiden (2010)

Wellershoff, F.: Nutzung der Verglasung zur Aussteifung von Gebäudehüllen. Dissertation, RWTH Aachen (2007) 